\title{
Oxygen free radicals in food
}

\author{
By Henry W.-S. Chan, AFRC Institute of Food Research, Norwich Laboratory, \\ Colney Lane, Norwich $\mathrm{NR}_{4}{ }_{7} U A$
}

The stability and nutritive value of many foods are affected by environmental molecular factors, of which the reaction between oxygen and unsaturated fatty acids remains the most significant in limiting the shelf-life of foods. It has been known for many years that $\mathrm{O}_{2}$ free radicals are involved in this oxidation process. The present paper reviews the formation and reactions of relevant $\mathrm{O}_{2}$ free radicals, including the recent developments concerning the pathways of the reactions of $\mathrm{O}_{2}$ free radicals with unsaturated fatty acids and to emphasize those reactions which are potentially most significant in food.

Food is essentially a biological material in which the organization is disrupted and other components added, in a controlled manner, to achieve the desired quality and nutritive value. It is thus a complex heterogeneous material often consisting of multiphasic components. Much of what is known about $\mathrm{O}_{2}$ free radicals in food has been derived from the study of simpler models which relate to systems that are discussed elsewhere in this symposium.

The $\mathrm{O}_{2}$ molecule has unusual properties which to a large extent limit the pathways in which oxidation of unsaturated compounds may take place. As a biological molecule, $\mathrm{O}_{2}$ has the unique property of having a triplet ground state, that is, a ground state in which there are two unpaired electrons having the same spin angular momentum. As a result of this, the direct addition of ground-state $\mathrm{O}_{2}$ to an unsaturated compound is not a permitted reaction between reactants in their ground states and, instead, oxygenation takes place by redox reactions or free-radical reactions, including free-radical chain reactions, and reactions including excited states of reactants. The reactions of $\mathrm{O}_{2}$ free radicals may be subdivided by their mode of formation, i.e. those that are generated by spin-allowed ground-state reactions and those that are generated by excited-state species; however, it is important to bear in mind that the division is somewhat artificial and that the two types of reactions very often occur side-by-side, especially in complex biological systems.

\section{Ground-state reactions}

$\mathrm{O}_{2}$ free radicals may be generated in ground-state reactions by redox, chain and enzyme reactions. Transition metals, for example iron in the lower oxidation state, participate readily in the reduction of $\mathrm{O}_{2}$ and thereby generate a number of $\mathrm{O}_{2}$ free radicals. The superoxide ion and hydroxyl radicals are also readily generated by redox-reactions and such reactions are important in, for example, the initiation of chain reactions. 
In the case of $\mathrm{O}_{2}$ radicals involved in chain reactions, there are three components to the mechanism, namely, initiation, propagation and termination.

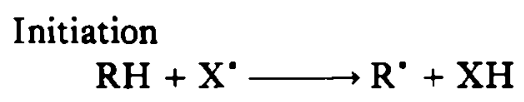

Propagation

$$
\left[\begin{array}{l}
\mathrm{R}^{\circ}+\mathrm{O}_{2} \longrightarrow \mathrm{ROO}^{\circ} \\
\mathrm{ROO}^{\circ}+\mathrm{RH} \longrightarrow \mathrm{R}^{\circ}+\mathrm{ROOH}
\end{array}\right.
$$

Termination

$\left.\begin{array}{l}\mathrm{R}^{\bullet}+\mathrm{R}^{\cdot} \longrightarrow \\ \mathrm{RO}_{2}^{+}+\mathrm{RO}_{2}^{+} \longrightarrow \\ \mathrm{RO}_{2}^{+}+\mathrm{R}^{\cdot} \longrightarrow\end{array}\right\}$ Stable products

The chain is initiated by the radical $\mathrm{X}^{*}$, which can be generated by a redox reaction. It can also be generated by many other reactions, such as high-energy radiation. The exact nature of the radical $\mathrm{X}^{*}$ in a given foodstuff is often very difficult to determine because of its very low concentration and also because of the fact that the important initiation reactions occur during the induction period in which the extent of oxidation is small and very difficult to measure. The propagation reaction, on the other hand, is the component in which the main products of oxidation are formed. This is also the component in which the radicals regenerate in a cycle of reactions. Apart from this important feature, the product, that is $\mathrm{ROOH}$, may also participate in the generation of radicals which act as $\mathrm{X}^{\circ}$ and hence initiate further chains. In other words, a further outer cycle of reactions may take place by autocatalysis or positive feedback. Some mechanisms of termination, which are by no means exhaustive, are shown above. Once started, the chain reaction turns over many, many times, very often thousands of times, before it is terminated and therefore the scheme as a whole occupies a central position in the oxidation of unsaturated lipids by whatever mechanism because even if radicals are generated by other means, such chains invariably take place to give rise to a mixture of mechanisms.

As the propagation step is the one that ultimately gives rise to the products, recent research has concentrated on the divergence of pathways within this step (Fig. I). In the case of polyunsaturated fatty acids, that is, those containing two or more double bonds separated by methylene groups, the $\mathbf{R}^{\circ}$ is a pentadienyl radical which, on oxygenation with $\mathrm{O}_{2}$, results in a peroxy radical. In the case of an unsaturated fatty acid such as linolenic acid, two types of peroxy radicals may be generated: those in which oxygenation takes place within the system of double bonds (the so-called 'inner peroxy radicals') or those in which the oxygenation takes place at the end of the unsaturated system (the so-called 'outer peroxy radicals'). Whereas both types of peroxy radicals may abstract hydrogen, either from another molecule of unsaturated fatty acid or from an added antioxidant, to 


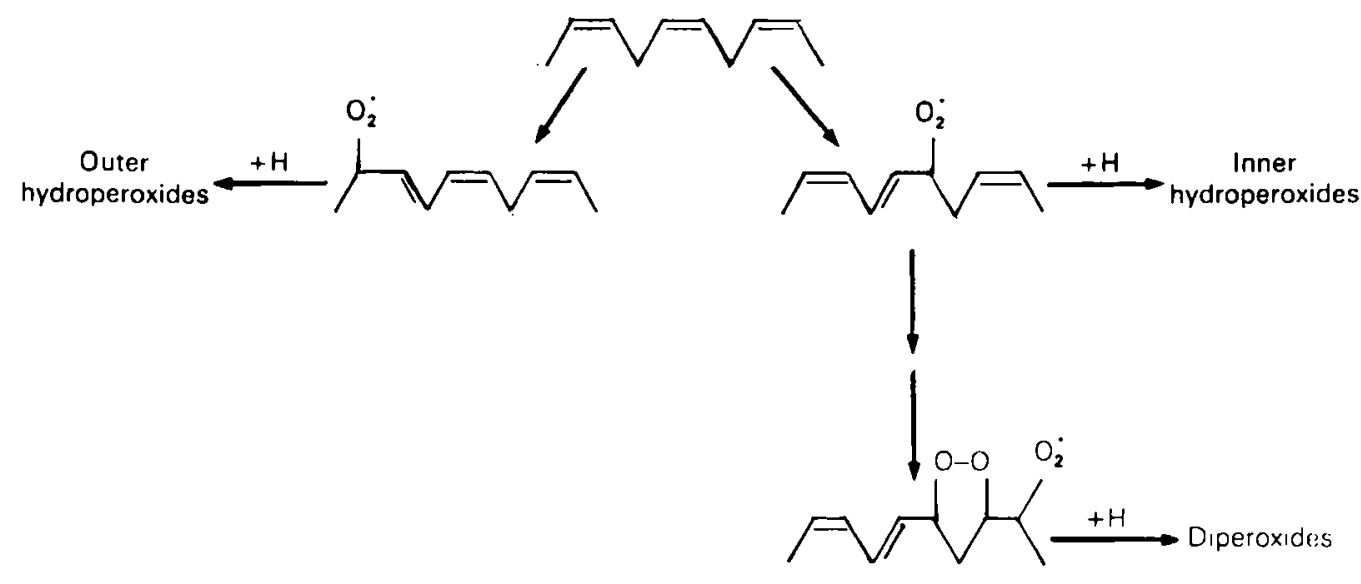

Fig. I. Propagation in chain reactions.

form a hydroperoxide, only the inner peroxy radicals may undergo further reactions to form the hydroperoxy epidioxides or diperoxides. Because of this divergence in the pathway, the action of $\mathrm{H}$ donors (amongst which are many important antioxidants) becomes important. The presence of significant quantities of a $\mathrm{H}$ donor quenches the first-formed peroxy radicals, thereby preventing their further reactions. This has the overall effect of increasing the proportion of hydroperoxides formed in the mixture of peroxy products at the expense of the diperoxides, which are dependent on further reactions of the peroxy radical. It also has the effect of increasing dramatically the relative proportion of inner hydroperoxides within the mixture. This is clearly demonstrated by adding increasing quantities of the antioxidant $\alpha$-tocopherol to autooxidizing methyl linolenate (Table $\mathrm{I}$ ). Thus in the presence of a $\mathrm{H}$ donor or antioxidant, two effects now become apparent. First of all, the overall rate of oxidation is decreased but, perhaps more significantly, the proportion of the different peroxidic products varies and, in the case of $\alpha$-tocopherol, increasing the concentration of the antioxidant has the effect of channelling the available $\mathrm{O}_{2}$ in favour of the formation of inner hydroperoxides. This may not necessarily have a beneficial effect. In at least one case, the presence of excess $\alpha$-tocopherol channels the formation of inner hydroperoxides which undergo further chemical decomposition in a food product to form a very specific taint (Swoboda \& Peers, 1979), rendering it undesirable.

In the case of reactions involving enzymes, there are many candidates for the generation and inhibition of $\mathrm{O}_{2}$ free radicals. For example, reduction of $\mathrm{O}_{2}$ may take place by $\mathrm{Fe}$-containing species and the concentration of $\mathrm{O}_{2}^{--}$thus formed controlled by superoxide dismutase ( $E C$ I.I 5.I.I). However, while these reactions no doubt occur, their significance in determining the stability of a food product is questionable because the reactions that are often most important occur either at very-low temperatures or in food products containing very-low water activities, 
Table I. Effect of a-tocopherol on the relative proportions of peroxidic products in the autooxidation of linolenate

$\begin{array}{ccccc}\begin{array}{c}\alpha \text {-Tocopherol } \\ \text { content } \\ (\mathrm{mg} / \mathrm{g})\end{array} & \begin{array}{c}\text { Extent of } \\ \text { oxidation } \\ (\mu \mathrm{mol} / \mathrm{g})\end{array} & \text { Diperoxides } & \begin{array}{c}\text { Inner } \\ \text { hydroperoxides }\end{array} & \begin{array}{c}\text { Outer } \\ \text { hydroperoxides }\end{array} \\ 00.0 & 665 & 0.382 & 0.111 & 0.507 \\ 00.5 & 42 & 0.237 & 0.244 & 0.519 \\ 5.0 & 74 & 0.75 & 0.426 & 0.499 \\ 50.0 & 469 & 0.000 & 0.530 & 0.470 \\ & & & \\ & & & \\ & & & \end{array}$

where most enzyme activity is minimal. Enzymes known to be important in a number of foodstuffs are the plant lipoxygenases. Although the lipoxygenases are now known to occur in animal tissue, their ubiquitous presence in significant quantities in most vegetable foods is a dominant factor. They exert their influence in three ways: (a) they are often responsible for the deterioration of vegetable foods in storage, even at low temperatures, because of the catalysed oxidation of unsaturated lipids; (b) they are responsible for the generation of the flavour in a number of vegetables; (c) in the technological arena, they are often added to improve the quality of baked products. The enzymes catalyse the reaction $\mathrm{RH} \rightarrow$ $\mathrm{ROOH}$ via the formation of $\mathrm{O}_{2}$ free radicals.

$$
\mathrm{RH} \stackrel{\mathrm{O}_{2}}{\longrightarrow} \text { (Radicals) } \longrightarrow \mathrm{ROOH}
$$

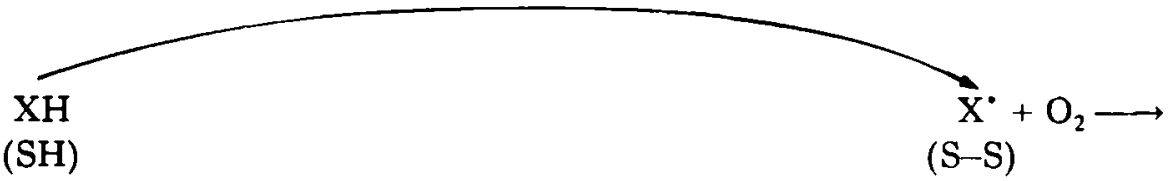

The free radicals that are formed are, however, accessible to other species in the system and in the 'coupled' oxidation of these other species, the enzyme-generated-enzyme-bound radicals act as an initiator of further oxidation, i.e., as $\mathrm{X}^{*}$. It is these coupled reactions in which, amongst other activities. sulphydryl compounds are oxidized to $\mathrm{S}-\mathrm{S}$ cross-linked species that give rise to the improvement of the quality of baked products. Two important features distinguish these enzyme-catalysed reactions from the chain reactions discussed previously. Firstly, although free radicals are formed, they are formed as part of an enzyme mechanism which, in itself, does not involve chains. Secondly, the product and the radicals formed are stereospecific and very often dependent on the species of plant or on the enzyme. Thus cucumbers (Cucumis sativus) taste like they do because the oxidation of unsaturated lipids that are present in them is catalysed by specific enzymes to give rise to specific products. As for the nature of the free radicals, they have been shown to involve the atom of $\mathrm{Fe}$ which is present in all the enzymes and 
to involve both the ferrous and ferric forms (Galliard \& Chan, 1980). It is perhaps worthwhile noting that the effects of enzyme-catalysed reactions are both positive and desirable as well as deleterious, that is, they are capable of generating desirable flavours and improving the quality of food as well as affecting their stability adversely.

\section{Reactions involving excited states}

Of the methods of generating excited states, three are most common, namely, photochemical reactions, exothermic oxidative reactions and high-energy radiation. Of these, in the case of food, photochemical reactions are perhaps the most prominent and, in the case of the oxidation of unsaturated lipids, two photochemical reactions may be considered, namely, direct photo-oxidation and sensitized photo-oxidation. Direct photo-oxidation is a reaction in which only light, $\mathrm{O}_{2}$ and the oxidized substrate are involved. Because the major components of food, i.e., protein, lipid and carbohydrate, do not absorb light of visible wavelengths normally and other wavelengths are often cut off by the packaging that is used, this type of photo-oxidation is of less significance. More important is the second kind in which, apart from $\mathrm{O}_{2}$, lipid and light, a fourth species is involved, which is often a dye that is either added or present naturally, which absorbs the light and transfers its energy into the other species, but is not itself oxidized. There are two types of sensitized photo-oxidations, of which type I involves the formation of an excited dye (dye") as the first step.

$$
\begin{aligned}
& \text { Dye }+\mathrm{h} v \longrightarrow \text { Dye }^{*} \\
& \text { Dye }^{*}+\mathrm{RH} \longrightarrow \text { Dye }^{\bullet}-\mathrm{H}+\mathrm{R}^{\bullet} \\
& \mathbf{R}^{\bullet}+\mathrm{O}_{2} \longrightarrow \mathrm{ROO}^{\bullet} \\
& \mathrm{ROO}^{\circ}+\text { Dye }-\mathrm{H}^{\bullet} \longrightarrow \mathrm{ROOH}+\text { Dye }
\end{aligned}
$$

Type I sensitized photo-oxidation

The excitation is then used to extract an $\mathrm{H}$ from the unsaturated lipid to form an $\mathrm{R}^{\cdot}$ and reaction of $\mathrm{R}^{\cdot}$ with the $\mathrm{O}_{2}$ molecule then follows as in the chain reaction discussed previously. The reaction is then terminated by, amongst others, reaction with the dye-bound $\mathrm{H}$ radical. In this mechanism, activation of the substrate is involved. In the type 2 mechanism, it is the $\mathrm{O}_{2}$ molecule which is activated.

$$
\begin{aligned}
& \text { Dye }+ \text { hv } \longrightarrow \text { Dye } \\
& \text { Dye }{ }^{*}+{ }^{3} \mathrm{O}_{2} \longrightarrow \text { Dye }{ }^{*}+{ }^{1} \mathrm{O}_{2} \\
& { }^{1} \mathrm{O}_{2}+\mathrm{RH} \longrightarrow \mathrm{ROOH}
\end{aligned}
$$

Type 2 sensitized photo-oxidation 
The dye in its excited state, after a process which is known as inter-system crossing, reacts with ground-state triplet $\mathrm{O}_{2}\left({ }^{3} \mathrm{O}_{2}\right)$ to give rise to a molecule of singlet excited-state $\mathrm{O}_{2}\left({ }^{1} \mathrm{O}_{2}\right)$ which, unlike the ground-state, may react directly with a molecule of an unsaturated lipid to form a hydroperoxide molecule. The two types of sensitized photo-oxidation may be differentiated by the products that are formed. In the case of the type I reaction, the products formed are identical to those of the chain reaction because of the involvement of the same intermediate, namely $\mathrm{R}^{\circ}$ and $\mathrm{ROO}^{\circ}$, and, for a I-4-diene such as linoleate, the 9- and the r 3 -conjugated hydroperoxides are formed. In the case of the type 2 reaction, however, ${ }^{1} \mathrm{O}_{2}$ reacts at both ends of any carbon-carbon double bonds that are present and, in the case of methyl linoleate, would give rise to a mixture of the 9-, I0-, I2- and I 3-isomers of hydroperoxides. They may also be distinguished by the inhibition of added antioxidants. In the case of the type 1 reaction, exemplified by riboflavin-sensitized photo-oxidation, addition of butylated hydroxytoluene (BHT) inhibits, partially, the oxidation of unsaturated lipid because of the quenching of the radicals that are formed (Chan, 1977). In the case of the type 2 reaction, exemplified by erythrosine-sensitized photo-oxidation, however, addition of BHT has no retarding effect but, rather, results in a small increase in $\mathrm{O}_{2}$ absorption at high levels of BHT due to the direct oxidation of BHT itself (Chan, 1975). In practice, often both types of sensitized photo-oxidation take place at the same time and their relative proportions differ, depending on the sensitizer, that is, the dye, and the conditions, such as the solvent and $\mathrm{pH}$, etc. In addition to a mixed mechanism of photosensitized oxidation, very often these photochemical reactions occur together with chain radical reactions because, as previously indicated, the hydroperoxides generated by the photochemical reaction may initiate dark reactions involving radical chains. This can be demonstrated by the occurrence of dark reactions when riboflavin is used as a sensitizer in the photo-oxidation of methyl linolenate (Chan, 1977). In the case of permitted food colours, erythrosine was found to be the only synthetic colour that sensitizes rapid oxidation of unsaturated lipids (Chan, 1975). This particular property of erythrosine can also be shown in a food product. When luncheon meat manufactured with or without any added erythrosine or with another red dye, Red $2 \mathrm{G}$, was subjected to irradiation by visible light, deterioration which was described as stale, staleness or rancidity was detected by a panel of assessors only in the case of the product containing erythrosine (Chan et al. 1977).

Finally, I would like to mention briefly the excited species that are generated by reactions other than photochemical reactions. Reactions of high-energy species such as hydroperoxides are thought to give rise occasionally to ${ }^{1} \mathrm{O}_{2}$, which would then react further as a chemical species as in the case of the type 2-sensitized photo-oxidation. Examples of three reactions involving $\mathrm{O}_{2}$ free radicals which are postulated to give rise to singlet ${ }^{1} \mathrm{O}_{2}$ are shown. 


$$
\begin{gathered}
2 \mathrm{ROOH} \longrightarrow 2 \mathrm{ROH}+{ }^{1} \mathrm{O}_{2} \\
2 \mathrm{HO}_{2}^{\circ} \longrightarrow \mathrm{H}_{2} \mathrm{O}_{2}+{ }^{1} \mathrm{O}_{2} \\
\mathrm{GS}^{\cdot}+\mathrm{GSOO}^{\cdot} \longrightarrow \mathrm{GSSG}^{\circ}{ }^{1} \mathrm{O}_{2} \\
+ \text { luminescence generated in } \mathrm{O}_{2} \text { radical reactions }
\end{gathered}
$$

It is worthwhile mentioning that whilst these reactions may occur in model systems, their occurrence to any significant extent in a food product has yet to be demonstrated. In addition to these reactions, high-energy excited species generated by $\mathrm{O}_{2}$ free radicals give rise to luminescence during the oxidation of unsaturated fatty lipids. In fact, the generated luminescence has been used in attempts to quantify or measure the extent of oxidation that has occurred within a given food product. Because of its potential use as a means of food preservation, mention should also be made of high-energy radiation. Because of the very high energy that is involved, processes that do not normally occur by ground-state or photochemical reactions may take place, for example:

$$
\begin{aligned}
& \mathrm{H}_{2} \mathrm{O} \longrightarrow \mathrm{H}^{\cdot}+\mathrm{OH}^{\cdot} \\
& \mathrm{H}_{2} \mathrm{O}+\mathrm{O}_{2} \longrightarrow \mathrm{H}_{2} \mathrm{O}^{+}+\mathrm{O}_{2}^{--}
\end{aligned}
$$

However, because of the very high reactivity of species such as $\mathrm{OH}^{*}$ and $\mathrm{H}_{2} \mathrm{O}^{+}$, the chemical reactions that involve these species will take place very rapidly and will be localized where they are generated. Of far greater significance is perhaps the ability of these species, or any free-radical species of lower energy generated by them, to initiate chains which, because of their self-generating nature, may be involved in far more significant reactions because of the much greater quantities of oxidized products that are formed.

\section{REFERENCES}

Chan, H. W.-S. (1975). Chemistry and Industry, 61 2-614.

Chan, H. W.-S. (1977). Fournal of the American Oil Chemists' Society 54, 100-104.

Chan, H. W.-S., Levett, G. \& Griffiths, N. M. (1977). Foumal of the Science of Food and Agriculture 28, 339-344.

Chan, H. W.-S. (1982). Food Chemistry 9, $21-34$.

Galliard, T. \& Chan, H. W.-S. (1980). In The Biochemistry of Plants, vol. 4, pp. I3I-I6I [P. K. Stumpf, editor]. London: Academic Press.

Swoboda, P. A. T. \& Peers, K. E. (1979). In Progress in Flavour Research, pp. 275-279 [D. G. Land and H. E. Nursten, editors]. London: Applied Science Publishers. 